\title{
Rubeosis Faciei Diabeticorum: a Common, but Often Unnoticed, Clinical Manifestation of Diabetes Mellitus
}

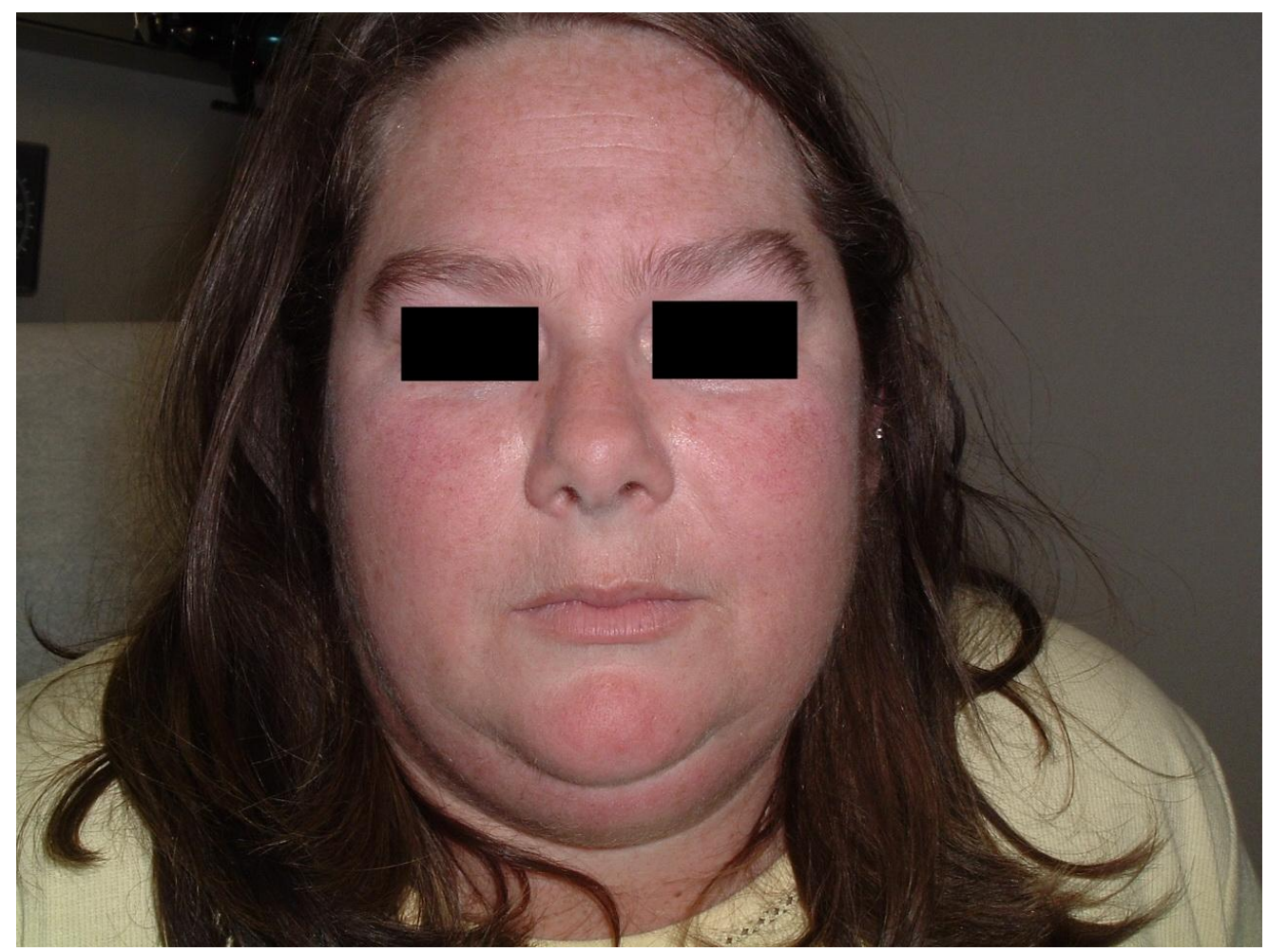

FIGURE. Rubeosis faciei diabeticorum in a patient with diabetes mellitus.

\author{
M.R. Namazi ${ }^{1}$, J.L. Jorizzo ${ }^{2}$, and M.K. Fallahzadeh ${ }^{1, *}$ \\ ${ }^{1}$ Dermatology Department, Shiraz University of Medical Sciences, Shiraz, Iran; \\ ${ }^{2}$ Dermatology Department, Wake Forest University Health Sciences, Winston- \\ Salem, North Carolina
}

E-mail: kazem.fa@gmail.com

Received November 3, 2009; Revised November 15, 2009; Accepted December 16, 2009; Published January 8, 2010

KEYWORDS: rubeosis faciei diabeticorum, diabetes mellitus, microangiopathy, hyperglycemia 
Rubeosis, also named rubeosis facei and rubeosis faciei diabeticorum, occurs in up to $59 \%$ of hospitalized patients with diabetes mellitus[1] and is often a sign of suboptimal glycemic control[2]. In diabetics, hyperglycemia could lead to sluggish microcirculation, which becomes clinically evident by facial venous dilatation[3]. Rubeosis signifies microangiopathy, necessitating the evaluation of the patients for other more important microangiopathies, such as retinopathy[2].

Strict glycemic control is the mainstay of treatment for this reddish complexion[2].

\section{REFERENCES}

1. Gitelson, S. and Wertheimer-Kaplinski, N. (1965) Color of the face in diabetes mellitus; observations on a group of patients in Jerusalem. Diabetes 14, 201-208.

2. Paron, N.G. and Lambert, P.W. (2000) Cutaneous manifestations of diabetes mellitus. Prim. Care 27, 71-83.

3. Huntley, A. (1995) Diabetes mellitus: review. Dermatol. Online J. 1(2). Address:

http://dermatology.cdlib.org/DOJvol1num2/diabetes/dmreview.html [accessed: November 12, 2009].

This article should be cited as follows:

Namazi, M.R., Jorizzo, J.L., and Fallahzadeh, M.K. (2010) Rubeosis faciei diabeticorum: a common, but often unnoticed, clinical manifestation of diabetes mellitus. TheScientificWorldJOURNAL: TSW Clinical Images 10, 70-71. DOI 10.1100/tsw.2010.11. 


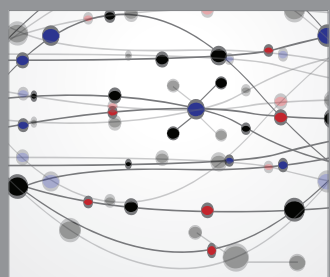

The Scientific World Journal
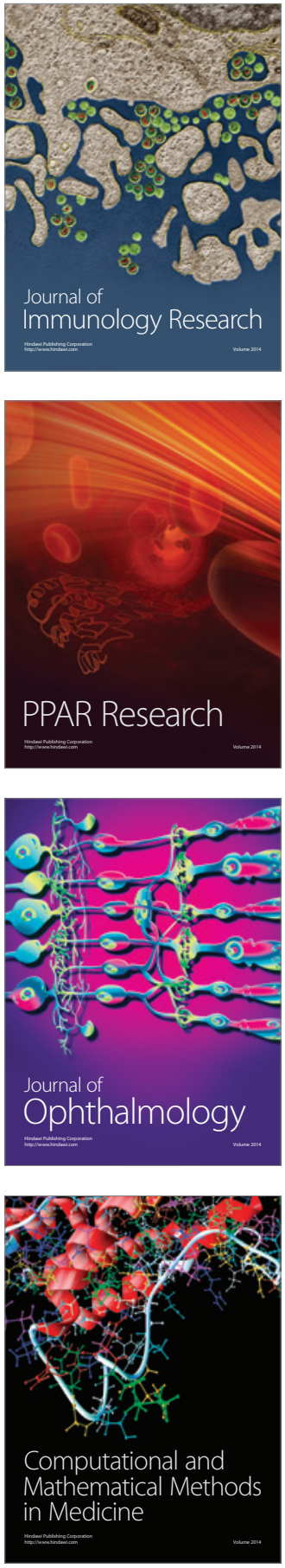

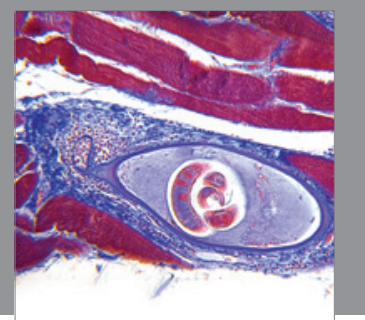

Gastroenterology

Research and Practice
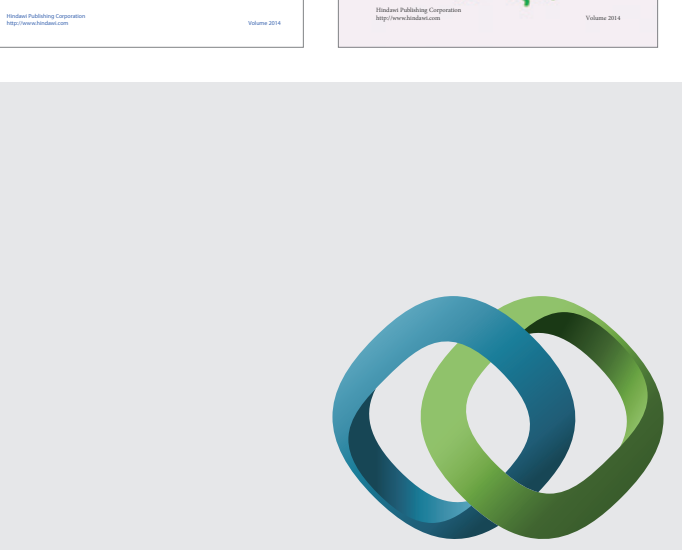

\section{Hindawi}

Submit your manuscripts at

http://www.hindawi.com
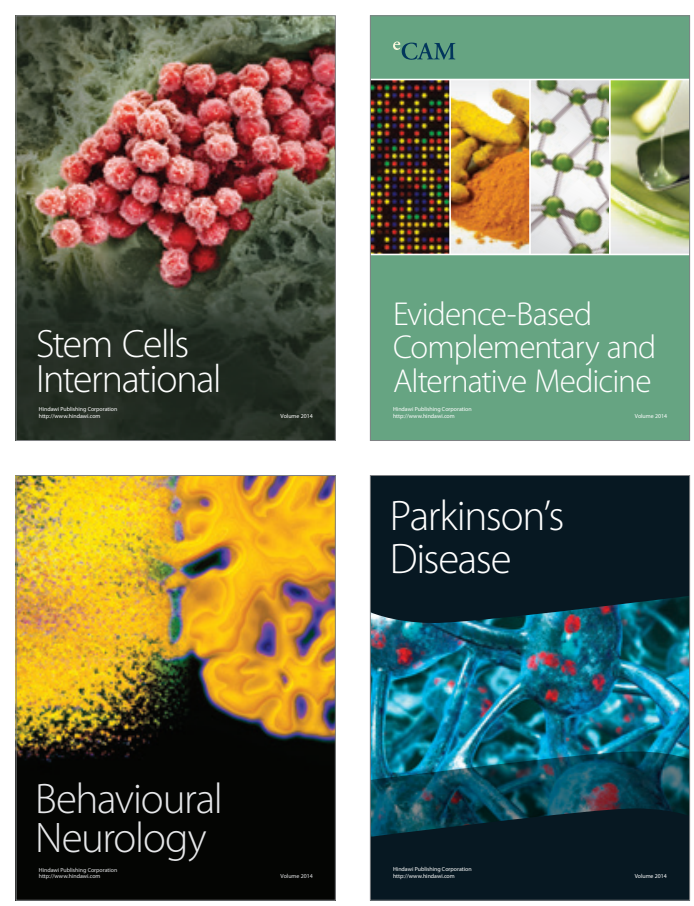

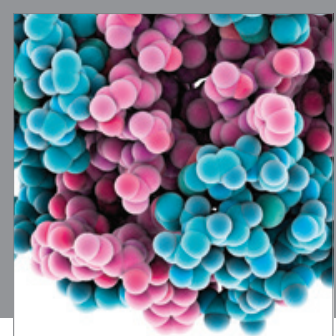

Journal of
Diabetes Research

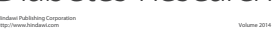

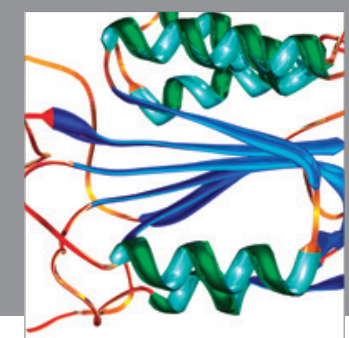

Disease Markers
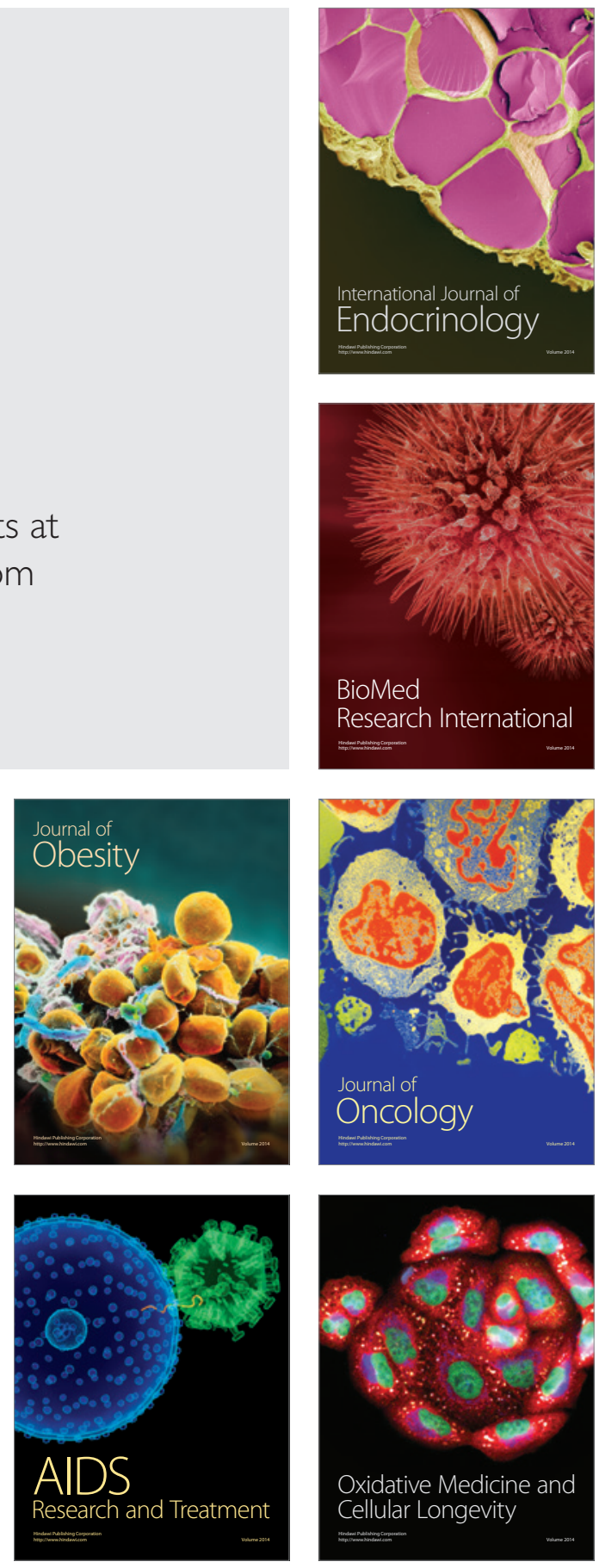